\title{
MECHANICAL, MORPHOLOGICAL AND THERMAL PROPERTIES OF
}

ALKALI TREATED GREWIA ORBICULATA ROTTLER FIBER

\section{N. C. SANDEEP ${ }^{1}$, H. RAGHAVENDRA RAO ${ }^{2} \&$ K. HEMACHANDRA REDDY ${ }^{3}$}

${ }^{1,3}$ Department of Mechanical Engineering, JNTU Anantapur, Andhra Pradesh, India

${ }^{2}$ Department of Mechanical Engineering, G Pulla Reddy Engineering College, Andhra Pradesh, India

\section{ABSTRACT}

This article manifests the extraction and characterization of uniaxial fibers from the barks of Grewia Orbiculata Rottler plant. Grewia fibers after retting were treated with 5\% sodium hydroxide solution. The alkali treated fibers were compared with untreated fibers with respect to their chemical composition, mechanical and thermal properties. From the obtained results, it was observed that alkali treated fibers showed better tensile properties and good thermal stability. From XRD studies, it was found that the alkali treated fibers showed high crystallinity. The change in surface morphology of fibers was observed after alkali treatment with scanning electron microscopy. Based on the properties observed for alkali treated Grewia Orbiculata Rottler fiber, it is expected that these fibers will be suitable in natural fiber composites as filler.

KEYWORDS: Grewia Orbiculata Rottler, Characterization, Physico-Chemical, Grewia \& Fiber

Received: Dec 30, 2017; Accepted: Jan 20, 2017; Published: Feb 28, 2018; Paper Id.: IJMPERDAPR201833

\section{INTRODUCTION}

Usage of synthetic fibers has polluted the planet to an alerting rate. Though there are many reasons for using synthetic fibers in polymer composites, there exist several drawbacks which include high cost, non-degradable nature, consumption of high energy which leads to problems such as environmental pollution, skin problems, etc. Several attempts have been made to restrict the usage of expensive synthetic fibers by using the plant fibers as fillers in composites. Most of the drawbacks can be overcome by using natural fibers in the place of synthetic fibers. The usage of naturally available products (fibers, agriculture wastes and wood) as reinforcement in green composites has been increased enormously, because of its biodegradable character, economical and high abundance in availability availability (N. C. Sandeep et al. 2017; Reddy et al. 2010; Thakur et al. 2010; Wambua et al. 2003). Poor compatibility between fiber and matrix has been one of the main problems ran across in using the natural fibers in composites (Singha and Rana 2012). This may be due to factors like highly hydrophilic character of the natural fibers or not having good adhesion between filler and matrix (Reddy et al. 2013 b, 2014). Therefore, proper mating of fiber and matrix is an important thing to get good properties from the composite. Several fiber surface modification methods are there to improve adhesion with polymer matrix (Singha et al., 2009). As the main attraction of today's market of fiber composites is the competitive cost of natural fibers, research on cost effective modification of natural fibers is essential (Kommula et al. 2013). Sodium hydroxide treatment for natural fibers is one of the less expensive and more efficient methods of surface modification techniques (Reddy et al. 2014). Improvement in mechanical properties of natural fibers on alkali treatment has been observed by many researchers (Mahuya Das, 2008). Effective removal of amorphous materials and impurities can be attained with alkali treatment (Reddy et al. 2013 a). It is rather important to evaluate the 
properties of newly identified natural fibers before using them as fillers in composites.

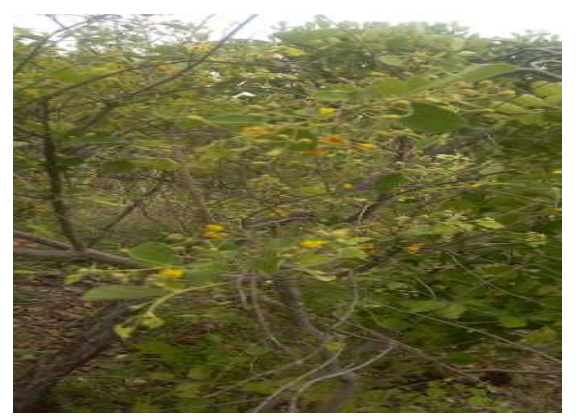

Figure 1: Grewia Orbiculata Rottler Plant

Grewia Orbiculata is an un-armed tree, well known as round leaved grewia belongs to Tiliaceae (phalsa family) and grewia (genus) as shown in Figure 1. The name Grewia Rotundifolia Juss. is the synonym of Grewia Orbiculata Rottler (accepted name). Leaves of Grewia Orbiculata plant have got medicinal importance. They are used to treat ulcers (Pullaiah et al. 2016). Bark extract of these plants can be used to treat diarrhea, smallpox, urinary troubles, and irritation in the bladder, gonorrhea and syphilis. Various parts of this tree are used in the treatment of eye ache, stomach ache and spleen troubles. The powder of its bark is used to treat wounds (Umberto Quattrocchi, 2014). This work is co-centered to characterization of new Grewia Orbiculata Rottler fiber as no previous studies were reported on this till date.

\section{MATERIALS AND METHODS}

\section{Materials Used}

Fiber layers extracted from the barks of Grewia Orbiculata Rottler plant, Sodium hydroxide, acetic acid, sodium chlorite and sodium bisulfate were the materials used.

\section{Methods}

\section{Extraction of Grewia Orbiculata Rottler fiber}

Grewia Orbiculata trees are widely spread in the Nallamala forest region in Kurnool district, Andhra Pradesh, India. Stem barks of these plants were gathered and were soaked in water for nearly two months. Uniaxial fiber layers were separated from their barks as shown in Figure 2. These extracted uniaxial fibers were dried to remove moisture.

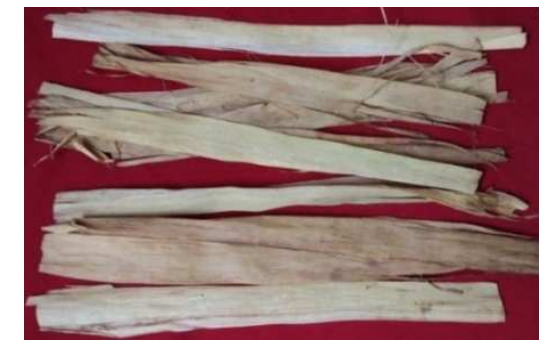

Figure 2: Uniaxial Layers of Extracted Grewia Orbiculata Rottler Fibers

\section{Alkali Treatment}

Extracted Grewia Orbiculata Rottler fibers were treated with 5\% sodium hydroxide solution for 30 minutes in order to remove the impurities and hemicellulose more effectively. Later, they were neutralized with acetic acid solution and thoroughly washed with de-ionized water, followed by oven dried at $100^{\circ} \mathrm{C}$ for $24 \mathrm{~h}$. 


\section{CHARACTERIZATION OF GREWIA ORBICULATA ROTTLER FIBER}

\section{Chemical Analysis}

The chemical composition of the fibers was determined according to the TAPPI standards [ $\alpha$-cellulose (T203 cm99), Lignin (T 222 om-06) and hemicellulose] (Chattopadhyay \& Sarkar, 1946; Macmillan et al. 1952; Sarkar et al. 1948).

\section{Fourier Transform Infra Red Spectroscopy (FTIR)}

Using Perkin Elmer 100S FTIR spectrophotometer, fourier transform infrared spectra were recorded in the range of 400-4000 $\mathrm{cm}^{-1}$ with $2 \mathrm{~cm}^{-1}$ resolution and 15 scans for each fiber sample. Samples of both alkali treated and untreated fibers were analyzed.

\section{X- Ray Diffraction Analysis}

Wide angle $\mathrm{X}$ ray diffractograms of alkali treated and untreated Grewia orbiculata rottler fibers were recorded on (X'Pert ${ }^{3}$ Powder) X ray diffraction system. The operating conditions of generator are $45 \mathrm{kV}$ and $30 \mathrm{~mA}$. The $2 \theta$ range of scanning the samples was from $6^{\circ}$ to $70^{\circ}$.

\section{Scanning Electron Microscopy}

Field emission scanning electron microscope (Merlin compact Zeiss) was used to observe the surface morphology of the fibers. The effect of alkali treatment was assessed using a comparison of the untreated and alkali treated fibers. The fibers were dried in an air oven at $60^{\circ} \mathrm{C}$ for $12 \mathrm{~h}$. The samples were then coated with gold using a vacuum sputter coater to avoid subsequent charging before measurement by SEM. The accelerating voltage was $20 \mathrm{kV}$.

\section{Tensile Testing}

The tensile properties of treated and untreated Grewia Orbiculata Rottler fibers were determined according to ASTM D5083 by using Instron 3369 Universal testing machine with a gauge length of $50 \mathrm{~mm}$ and a crosshead speed of 5 $\mathrm{mm} / \mathrm{min}$. Five samples were tested for each fiber.

\section{Thermogravimetric Analysis}

The thermograms of untreated and alkali treated Grewia Orbiculata Rottler fibers were recorded using a thermogravimetric analyzer Perkin Elmer, USAA of model Diamond TG/DTA at IIT Bombay. Samples below $5 \mathrm{mg}$ each were placed in platinum pans and were heated from room temperature to $700^{\circ} \mathrm{C}$ at $10^{\circ} \mathrm{C} \mathrm{min}^{-1}$.

\section{RESULTS AND DISCUSSIONS}

\section{Chemical Analysis}

The chemical compositions of $\mathrm{NaOH}$ treated and untreated Grewia Orbiculata Rottler fibers were determined and reported in Table 1.

Table 1: Chemical Compositions of Grewia Orbiculata Rottler Fibers

\begin{tabular}{|l|c|c|}
\hline \multicolumn{1}{|c|}{ Parameter } & Untreated Fiber & Alkali Treated Fiber \\
\hline$\alpha$ - Cellulose (\%) & 60.45 & 71.13 \\
\hline Hemicellulose (\%) & 23.54 & 16.58 \\
\hline Lignin (\%) & 15.99 & 12.26 \\
\hline
\end{tabular}


It was reported that diluted alkali treatment was performed to hydrolyze lignin, pectin, hemicelluloses and proteins by $\beta$-elimination process to soluble them, because naturally they are not soluble in any aqueous medium (Dufresne et al. 1997). When the fibers were treated with alkali solution, partly hydrolization of hemicellulose takes place and depolymerization of lignin, giving rise to phenolic resin and sugar compounds which are soluble in water partially (Fernández-Bolaños et al. 1999). Because of cleavage of ether linkages between hemicellulose and lignin by alkali treatment, high solubility took place between hemicellulose and lignin (Xiao et al. 2001). As the alkali treatment was efficient enough to remove hemicellulose in the fiber, a decrease in hemicellulose component from 23.54 to $16.58 \%$ was observed. It was reported that the chemical composition values are comparable with the results reported by Reddy et al. and John et al. (John \& Anandjiwala, 2008; Obi Reddy et al. 2013 a; Reddy et al. 2014; Reddy, et al. 2012 b). Where cellulose content of Grewia Orbiculata Rottler fiber is higher than that of borassus, coir, napier and bamboo fibers and lower than the rest of the fibers reported. The content of hemicellulose in Grewia Orbiculata rottler fiber is lower than that of thespesia, borassus, napier and bamboo fibers and higher than the rest of the fibers reported. Whereas the lignin content of Grewia Orbiculata fibers is lower than that of bamboo, borassus, coir, napier and oil palm fibers and higher than that of remaining fibers reported in the literature.

\section{Fourier Transform Infra Red Spectroscopy}

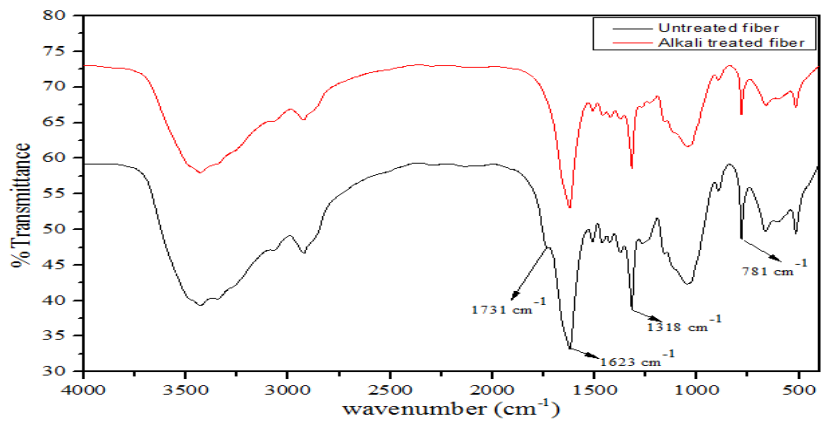

Figure 3: FT-IR of Untreated and Alkali Treated Grewia Orbiculata Rottler Fibers

Figure 3 shows the comparison of the FTIR spectra of alkali treated and untreated Grewia Orbiculata Rottler fiber. Peaks at $2925 \mathrm{~cm}^{-1}$ and $3431 \mathrm{~cm}^{-1}$ correspond to alkyl C-H stretching and O-H stretching of $\alpha$-cellulose respectively. The peak at $1731 \mathrm{~cm}^{-1}$ represents $\mathrm{C}=\mathrm{O}$ stretching of hemicellulose. Peaks corresponding to lignin at $781 \mathrm{~cm}^{-1}, 1318 \mathrm{~cm}^{-1}$ and $1623 \mathrm{~cm}^{-1}$ represents aromatic $\mathrm{C}-\mathrm{H}$ stretching, asymmetric $\mathrm{C}-\mathrm{O}-\mathrm{C}$ stretching and $\mathrm{C}=\mathrm{O}$ stretching of lignin respectively (Avérous \& Le Digabel, 2006; Pandey, 1999). With the above mentioned peaks, it was evident that the presence of $\alpha$ cellulose, hemicellulose and lignin in the grewia orbiculata rottler fiber. Peak at $1731 \mathrm{~cm}^{-1}$ for raw (untreated) fiber which represents hemicellulose disappeared with alkali treatment. For alkali treated fibers, the peak intensities which represents lignin at $781 \mathrm{~cm}^{-1}, 1318 \mathrm{~cm}^{-1}$ and $1623 \mathrm{~cm}^{-1}$ decreased when compared the corresponding peaks of raw fiber (Eojewska et al. 2005; Ray \& Sarkar, 2001). This means the reduction of hemicellulose and lignin content was observed in the alkali treated fibers. Therefore, these results are compatible with that of Chemical analysis.

\section{Ray Diffraction Analysis}

To examine the crystalline nature of the Grewia Orbiculata Rottler fiber, X-ray diffraction studies were carried out. The major crystalline peak was observed at $2 \theta=24.43^{\circ}$ as shown in Figure 4 . This peak represents the crystallographic plane of cellulose. 


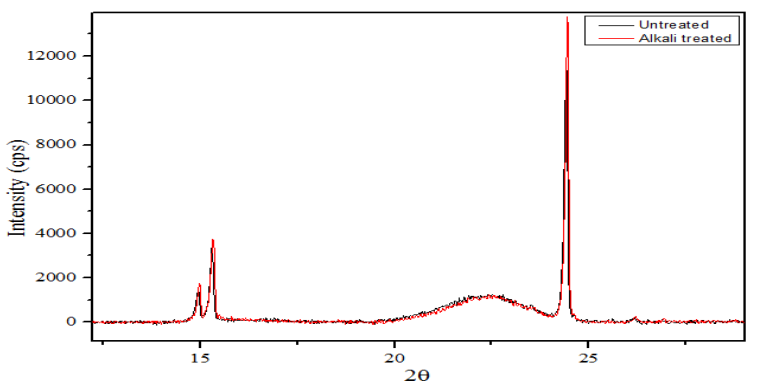

\section{Figure 4: X Ray Diffractograms of Untreated and} Treated Grewia Orbiculata Rottler Fibers

After alkali treatment, the intensity of Grewia Orbiculata Rottler fiber at this plane was increased. Other major peak was observed at $2 \theta=15.35^{\circ}$. This reflection corresponds to the crystallographic plane (110). The crystallinity index $\left(\mathrm{I}_{\mathrm{C}}\right)$ for untreated and treated Grewia orbiculata rottler fibers were calculated using the following equation.

$$
\mathrm{I}_{\mathrm{C}}=\left[\left(\mathrm{I}_{002}-\mathrm{I}_{\mathrm{am}}\right) / \mathrm{I}_{002}\right] \times 100
$$

Where $\mathrm{I}_{002}$ and $\mathrm{I}_{\mathrm{am}}$ are the intensities of the peaks at $2 \theta=24.43^{\circ}$ (crystalline phase) and $15.35^{\circ}$ (amorphous phase) respectively. The crystallnity indices for alkali treated and untreated Grewia orbiculata rottler fibers were found to be 73.05 and 69.85 respectively. The increase in the crystallanity index in alkali treated fiber is due to the removal of amorphous portions in the fiber when treated with sodium hydroxide and thereby rearranging the crystalline portions in the fiber.

\section{Scanning Electron Microscopy Analysis}

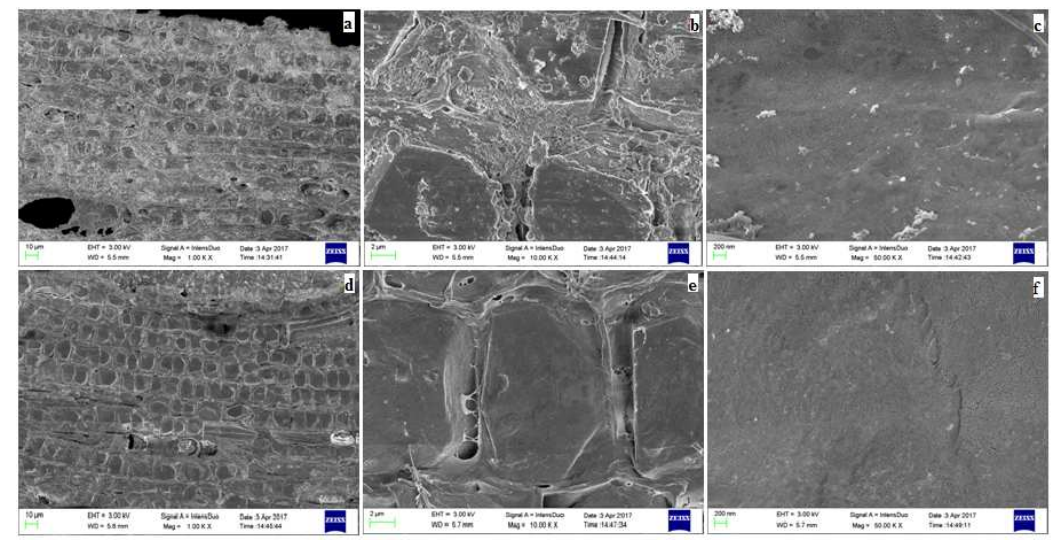

Figure 5: (a), (b),(c) Untreated (d),(e),(f) Alkali Treated SEM Images of Grewia Orbiculata Rottler Fibers

Scanning electron micrographs of $\mathrm{NaOH}$ treated and untreated Grewia orbiculata rottler fiber were shown in Figure 5. After treating fibers with sodium hydroxide, partial removal of amorphous materials like hemicellulose, wax, lignin, etc., took place resulting rough fiber surface. The same was observed by cintil (Chirayil et al., 2014). This enhances the good adhesion between fiber and matrix. Parenchyma cells type structure was observed at $2 \mu \mathrm{m}, 10 \mathrm{KX}$ magnifications which were arranged in a regular manner. 


\section{Tensile Properties}

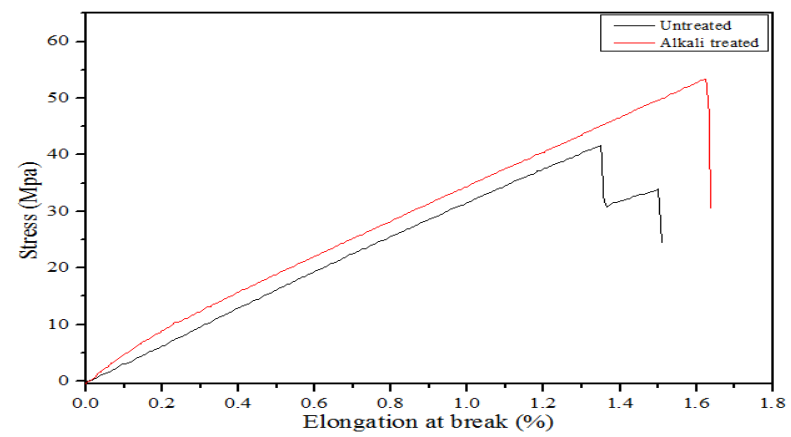

Figure 6: Stress- Strain Graph of Untreated and Alkali Treated Grewia Orbiculata Rottler Fibers

From Figure 6, it can be observed that the stress strain graph for both untreated and alkali treated Grewia Orbiculata Rottler fibers is linear up to failure. Tensile properties of Grewia orbiculata rottler fibers were evaluated before and after alkali treatment in Table 2.

Table 2: Tensile Properties of Grewia Orbiculata Rottler Fibers

\begin{tabular}{|l|c|c|}
\hline \multicolumn{1}{|c|}{ Tensile Properties } & Untreated Fiber & Alkali Treated Fiber \\
\hline Tensile stress (Mpa) & 41.68 & 53.39 \\
\hline Young's Modulus (Gpa) & 3.32 & 4.39 \\
\hline Elongation at break (\%) & 1.50 & 1.62 \\
\hline
\end{tabular}

The tensile strength for alkali treated and untreated Grewia Orbiculata Rottler fiber is 53.39 Mpa and 41.68 Mpa respectively. Increase in tensile properties like tensile strength, modulus and elongation at break were observed. Increase in tensile strength by $26.8 \%$ was observed after alkali treatment. This change may be due to the bust of bonds between hemicelluloses and cellulose, as those bonds were so sensitive enough to the sodium hydroxide, giving tend to the transfer of stress within inter febrile areas.

\section{Thermogravimetric Analysis}

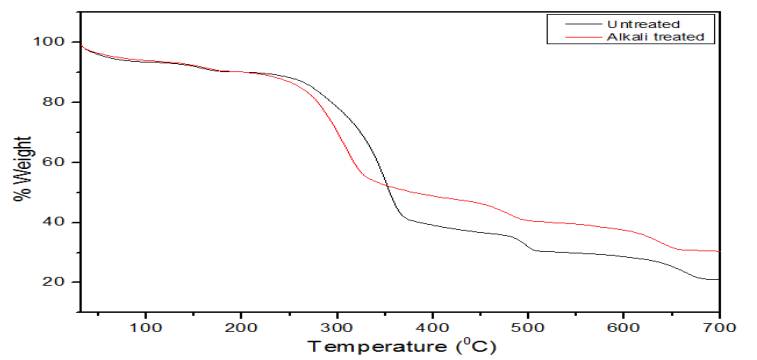

Figure 7: Primary Thermograms of Untreated and Alkali Treated Grewia Orbiculata Rottler Fibers

The thermal stability of treated and untreated Grewia orbiculata rottler fibers was investigated by Thermo gravimetric analysis. Primary thermograms of treated and untreated fibers are shown in Figure 7. The moisture content in the fibers was removed up to $150^{\circ} \mathrm{C}$. The percentage content of moisture present in the untreated fibers was $9.6 \%$ and for alkali treated fibers, it was $9.4 \%$. The reduction in the moisture content for treated fibers was due to decrease in the number of free hydroxyl groups after alkali treatment (Reddy et al. 2012 a). The fiber degradation took place in three stages, 
indicating the presence of different constituents (Yang et al. 2007). For both treated and untreated fibers, the first level of degradation was started at temperature $200^{\circ} \mathrm{C}$ and took up to $325^{\circ} \mathrm{C}$ for treated and $365^{\circ} \mathrm{C}$ for untreated fibers. This first level of degradation is about the loss of hemicellulose and small amount of lignin. The second level of degradation range of temperatures from 365 to $505^{\circ} \mathrm{C}$ for untreated and 325 to $495^{\circ} \mathrm{C}$ for alkali treated fibers. This level of degradation corresponds to the cellulose degradation. The third level of degradation range of temperature from 505 to $680^{\circ} \mathrm{C}$ for untreated and 495 to $660^{\circ} \mathrm{C}$ for alkali treated fibers. Degradation of lignin is difficult. Its decomposition starts from 200 to $700^{\circ} \mathrm{C}$. $50 \%$ degradation temperature was at $352.5^{\circ} \mathrm{C}$ and $382.5^{\circ} \mathrm{C}$ for untreated and treated fibers respectively. The percentage char content was increased from $20.71 \%$ to $30 \%$ when treated the fibers with sodium hydroxide. This may be due to the reason that after alkali treatment, hemicellulose was removed which makes the cellulose-lignin complex more stable when compared to untreated fiber, which in turn reflected the increased content of the residual char (Reddy et al. 2009).

\section{CONCLUSIONS}

Uni-axial fiber layers were extracted from the barks of Grewia Orbiculata Rottler plant by water retting method and characterized in detail. Extracted fibers were subjected to 5\% sodium hydroxide treatment to examine the effect of alkali treatment on chemical composition, crystallinity, surface morphology, thermal and tensile properties. Surface morphology revealed the rough end surface of fiber after alkali treatment due to the removal of hemicellulose and greasy impurities. Results were supported by FTIR and Chemical analysis. Increase in the crystallinity index after alkali treatment was indicated through X-ray studies. Improved thermal stability and tensile properties of Grewia Orbiculata Rottler fibers due to the bust of bonds between hemicelluloses and cellulose, as those bonds were so sensitive enough to the sodium hydroxide, giving tends to the transfer of stress within inter febrile areas. Therefore, Grewia Orbiculata Rottler fibers can be used as fillers in green composites after proper alkali treatment as per the requirement. On the otherhand, this would enhance the development of plantation of these species which has got more medicinal applications.

\section{REFERENCES}

1. Avérous, L., \& Le Digabel, F. (2006). Properties of biocomposites based on lignocellulosic fillers. Carbohydrate Polymers, 66(4), 480-493.

2. Chattopadhyay, H., \& Sarkar, P. B. (1946). A new method for the estimation of cellulose. Proceedings of the National Institute of Sciences of India, 12(1), 23-46.

3. Chirayil, C. J., Joy, J., Mathew, L., Mozetic, M., Koetz, J., \& Thomas, S. (2014). Isolation and characterization of cellulose nanofibrils from Helicteres isora plant. Industrial Crops and Products, 59, $27-34$.

4. Dufresne, A., Cavaille, J.-Y., \& Vignon, M. R. (1997). Mechanical behavior of sheets prepared from sugar beet cellulose microfibrils. Journal of Applied Polymer Science, 64(6), 1185-1194.

5. Fernández-Bolaños, J., Felizón, B., Herediaz. ast, A., Guillén, R., \& Jiménez, A. (1999). Characterization of the lignin obtained by alkaline delignification and of the cellulose residue from steam-exploded olive stones. Bioresource Technology, 68(2), 121-132.

6. John, M. J., \& Anandjiwala, R. D. (2008). Recent Developments in Chemical Modification and Characterization of Natural Fiber-Reinforced Composites. Polymer Composites, 29(2), 187-207. 
7. Kommula, V. P., Reddy, K. O., Shukla, M., Marwala, T., \& Rajulu, A. V. (2013). Physico-chemical, Tensile, and Thermal Characterization of Napier Grass (Native African) Fiber Strands. International Journal of Polymer Analysis and Characterization, 18(4), 303-314.

8. Łojewska, J., Miśkowiec, P., Łojewski, T., \& Proniewicz, L. M. (2005). Cellulose oxidative and hydrolytic degradation: In situ FTIR approach. Polymer Degradation and Stability, 88(3), 512-520.

9. Macmillan, W. G., Gupta, A. B. Sen, \& Roy, A. (1952). 8-Observations on the Determination of Lignin in Jute. Journal of the Textile Institute Transactions, 43(3), T103-T111.

10. Mahuya Das, D. C. (2008). Evaluation of Improvement of Physical and Mechanical Properties of Bamboo Fibers Due to Alkali Treatment. Journal of Applied Polymer Science, 107, 522-527.

11. N. C. Sandeep., Raghavendra Rao, H., \& Hemachandra Reddy, K. (2017). Extraction and Characterization of Physicochemical and Tensile Properties of Aegle Marmelos fiber. Materials Today: Proceedings, 4(2), 3158-3165.

12. Reddy, K. O., Shukla, M., Uma Maheswari, C., \& Varada Rajulu, A. (2012 a). Mechanical and physical characterization of sodium hydroxide treated Borassus fruit fibers. Journal of Forestry Research, 23(4), 667-674.

13. Reddy, K. O., Sivamohan Reddy, G., Uma Maheswari, C., Varada Rajulu, A., \& Madhusudhana Rao, K. (2010). Structural characterization of coconut tree leaf sheath fiber reinforcement. Journal of Forestry Research, 21(1), 53-58.

14. Reddy, K. O., Uma Maheswari, C., Shukla, M., Song, J. I., \& Varada Rajulu, A. (2013 a). Tensile and structural characterization of alkali treated Borassus fruit fine fibers. Composites Part B: Engineering, 44(1), 433-438.

15. Pandey, K. K. (1999). A study of chemical structure of soft and harwood and wood polymers by FTIR spectrscopy. Journal of Applied Polymer Science, 71(May), 1969-1975.

16. Pullaiah, T., K. V. Krishnamurthy., bin bahadur. (2016). Ethnobotany of India, Volume 2: Western Ghats and West Coast of Peninsular India. In Ethnobotany of India, Volume 2: Western Ghats and West Coast of Peninsular India (p. 156). CRC press.

17. Ray, D., \& Sarkar, B. K. (2001). Characterization of alkali-treated jute fibers for physical and mechanical properties. Journal of Applied Polymer Science, 80, 1013-1020.

18. Reddy, K. O., Ashok, B., Reddy, K. R. N., Feng, Y. E., Zhang, J., \& Rajulu, A. V. (2014). Extraction and Characterization of Novel Lignocellulosic Fibers From Thespesia Lampas Plant. International Journal of Polymer Analysis and Characterization, 19(1), 48-61.

19. Reddy, K. O., Maheswari, C. U., Reddy, D. J. P., \& Rajulu, A. V. (2009). Thermal properties of Napier grass fibers. Materials Letters, 63(27), 2390-2392.

20. Reddy, K. O., Maheswari, C. U., Shukla, M., \& Rajulu, A. V. (2012 b). Chemical composition and structural characterization of Napier grass fibers. Materials Letters, 67(1), 35-38.

21. Reddy, K. O., Reddy, K. R. N., Zhang, J., Zhang, J., \& Varada Rajulu, A. (2013 b). Effect of Alkali Treatment on the Properties of Century Fiber. Journal of Natural Fibers, 10(3), 282-296.

22. Sarkar, P. B., Mazumdar, A. K., \& Pal, K. B. (1948). 4???The hemicelluloses of jute fibre. Journal of the Textile Institute Transactions, 39(2), T44-T58.

23. Singha, A. S., \& Rana, A. K. (2012). Improvement of Interfacial Adhesion in Cannabis indica/Unsaturated Polyester Biocomposites through Esterification Reaction. International Journal of Polymer Analysis and Characterization, 17(8), 590599. 
24. Singha, A. S., Thakur, V. K., Mehta, I. K., Shama, A., Khanna, A. J., Rana, R. K., \& Rana, A. K. (2009). Surface-modified Hibiscus sabdariffa fibers: Physicochemical, thermal, and morphological properties evaluation. International Journal of Polymer Analysis and Characterization, 14(8), 695-711.

25. Thakur, V. K., Singha, A. S., \& Mehta, I. K. (2010). Renewable resource-based green polymer composites: Analysis and characterization. International Journal of Polymer Analysis and Characterization, 15(3), 137-146.

26. Umberto Quattrocchi, F. L. S. (2014). CRC World Dictionary of medicinal and poisonous plants. In CRC World Dictionary of medicinal and poisonous plants (p. 524). CRC press Newyork.

27. Wambua, P., Ivens, J., \& Verpoest, I. (2003). Natural fibres: Can they replace glass in fibre reinforced plastics? Composites Science and Technology, 63(9), 1259-1264.

28. Xiao, B., Sun, X. F., \& Sun, R. (2001). Chemical, structural, and thermal characterizations of alkali-soluble lignins and hemicelluloses, and cellulose from maize stems, rye straw, and rice straw. Polymer Degradation and Stability, 74(2), 307-319.

29. Yang, H., Yan, R., Chen, H., Lee, D. H., \& Zheng, C. (2007). Characteristics of hemicellulose, cellulose and lignin pyrolysis. Fuel, 86(12-13), 1781-1788. 
